\title{
TRANSPARÊNCIA MORFOLÓGICA, COMPOSICIONALIDADE SEMÂNTICA E REANÁLISE ESTRUTURAL EM VERBOS DO PORTUGUÊS
}

\author{
Morphological transparency, semantic \\ compositionality and structural reanalysis in verbs \\ of portuguese
}

\author{
Indaiá de Santana Bassani*
}

\begin{abstract}
RESUMO
O objetivo deste artigo é investigar formações verbais parcialmente transparentes, no que diz respeito à estrutura morfológica, e duvidosas quanto ao fato de serem semanticamente composicionais. Dentre os 53 verbos estudados, alguns exemplos são: atrair, extrair e embutir. Como resultado do estudo, apresentamos uma proposta de classificação empírica em subtipos verbais de acordo com o grau de transparência morfológica e a contribuição semântica dos possíveis prefixos e das raízes que os formam, a saber: verbos parcialmente transparentes com raiz inativa; verbos parcialmente transparentes com raiz ativa não-analisáveis; verbos parcialmente transparentes com raiz ativa analisáveis. A classificação se baseia, sobretudo, em evidência empíricas morfológicas. A análise para os casos de mudança, largamente conhecidos como casos de lexicalização, se baseia na ideia de reanálise estrutural em uma abordagem sintática para formação de palavras. Mostramos que existe um continuum entre as formações completamente fossilizadas, reanalisadas como simples, e as formações em processo de

* Universidade Federal de São Paulo.
\end{abstract}


mudança, comparamos esse processo ao de desaparecimento de preverbos e sugerimos que essa mudança pode ser explicada em termos de perda de estrutura nos termos de Roberts e Roussou (2003).

Palavras-chave: transparência morfológica; composicionalidade semântica; reanálise estrutural.

\begin{abstract}
The aim of this paper is to investigate partially transparent verbal formations, in what regards their morphological structure, and doubtful as to whether they are semantically compositional. Among the 53 verbs studied, some examples are: atrair (attract), extrair (extract) and embutir (embed). As a result of the study, we propose an empirical classification of subtypes of verbs according to their degree of morphological transparency and semantic contribution of possible prefixes and roots that form them, namely: partially transparent verbs with inactive root; partially transparent non-analyzable verbs with active root; partially transparent analyzable verbs with active root. The classification is based mostly on morphological empirical evidence. The analysis for cases of change, widely known as cases of lexicalization, is based on the idea of structural reanalysis under a syntactic approach to word formation. We show that there is a continuum among formations, from completely fossilized, reconsidered as simple to those in process of change, and we compare this process to the process of preverbs disappearance and suggest that this change can be explained in terms of loss of structure, according to Roberts and Roussou (2003) proposal.
\end{abstract}

Keywords: morphological transparency; semantic compositionality; structural reanalysis.

\title{
1. INTRODUÇão
}

Uma palavra derivada completamente transparente e composicional é aquela em que se pode reconhecer formal e funcionalmente tanto a contribuição individual de cada afixo quanto a da base ou raiz. Por isso, o resultado (morfológico e semântico) da combinação é previsível a partir das partes componentes. Abaixo, apresentamos alguns exemplos de verbos morfologicamente derivados com morfologia transparente e semântica composicional do português (em ao menos uma de suas leituras): 
Amanhecer: [a-[MANH( $\left.(\tilde{\mathrm{A}}) \mathrm{N}]-\mathrm{ec}-\left(\mathrm{er}^{1}\right)\right] \mathrm{V}$

(2) Ensurdecer: [en-[SURDOA]-ec-(er)] V

(3) Esfriar: [es-[FRIOA]- $\varnothing-(\operatorname{ar})] \mathrm{V}$

Já nos casos dos verbos expostos em (4), abaixo, nota-se a presença formal de um elemento inicial homófono aos prefixos a-, em- e ex-, porém a contribuição desses possíveis prefixos não é evidente. Por isso, o sinal de interrogação após a sua nomeação como derivados.
Verbos derivados?
a. atrair
b. embutir
c. extrair

Nesses verbos, que vamos considerar parcialmente transparentes, é possível reconhecer um afixo do ponto de vista formal (morfológico) em um exercício analítico diacrônico, mas sua contribuição sincrônica não é óbvia. São exemplares desta categoria os seguintes verbos: atrair, extrair, incluir, excluir, inalar, exalar, acessar, afetar, embutir, esquecer, inflamar etc.

Uma primeira pergunta que se coloca é se tais dados seriam relevantes para uma teoria de descrição da língua, já que análises sintáticas para a formação de palavras têm se debruçado somente sobre dados completamente transparentes e cuja composicionalidade semântica é completa, com algumas discussões sobre leituras idiossincráticas dessas formações (como em ARAD (2003) e MARANTZ (2007)). Mais especificamente, discutiremos a questão tendo como base a teoria da Morfologia Distribuída (MD) (HALLE; MARANTZ, 1993).

Consideramos que essa é uma questão que merece atenção, pois muitas críticas a modelos sintáticos (que vêm de abordagens tradicionalistas) dizem que abordagens sintáticas nada têm a dizer sobre tais dados. Assim, a questão mais profunda que investigamos neste artigo é: como podemos explicar os dados parcialmente transparentes em uma teoria como a da MD sem simplesmente dizer que se trata de diacronia e, logo, que são dados fora de escopo? Outra forma de evitar retoricamente tais dados emerge quando os autores trazem à tona o rótulo de formas lexicalizadas e descartam sua investigação.

Propomos um estudo desses casos porque há poucas propostas formais para explicar o processo de lexicalização em morfologia e pelo desafio

1 Utilizamos como forma de representação a combinação dos morfemas de vogal temática e infinitivo.

Revista Letras, Curitiba, n. 91 p. 109-130, JAN./JUN. 2015.

ISSN 2236-0999 (VERSÃo ELETRÔNICA) 
que tais dados representam, em tese, para uma teoria como a MD; em outras palavras, como a MD lida com a ideia de lexicalização? Em suma, queremos explorar os mecanismos pelos quais as palavras deixam de ser derivadas para se tornarem simples e quais são as consequências desse processo. Mais especificamente, exploramos como se dá o processo pelo qual a estrutura composicional dos verbos derivados deixa de ser transparente.

Neste artigo, temos como objetivo empírico investigar verbos como os apresentados em (4). Como resultado, apresentamos uma proposta de classificação para tais verbos possivelmente derivados em subtipos de acordo com o grau de transparência morfológica e a contribuição semântica dos possíveis prefixos e das raízes que os formam. A proposta de análise do artigo se baseia em reanálise estrutural a partir de uma abordagem sintática para formação de palavras. Não trataremos neste artigo da classificação e da análise de verbos derivados com morfologia transparente e semântica composicional e não-comsposicional (cf. BASSANI, 2013).

\section{Proposta de classificação}

O diagrama abaixo sumariza a nossa proposta geral de classificação dos dados para verbos parcialmente transparentes, que será explicada nas próximas subseções. Analisamos 53 verbos possivelmente derivados do português, que foram subclassificados em verbos parcialmente transparentes com raiz inativa e verbos parcialmente transparentes com raiz ativa não analisável e analisável. Para a metodologia de seleção dos dados, cf. Bassani (2013, seção 1.6, p. 25-30). Para o conjunto total investigado neste artigo, cf. anexo I.

Diagrama 1 - Proposta geral de classificação de verbos parcialmente transparentes

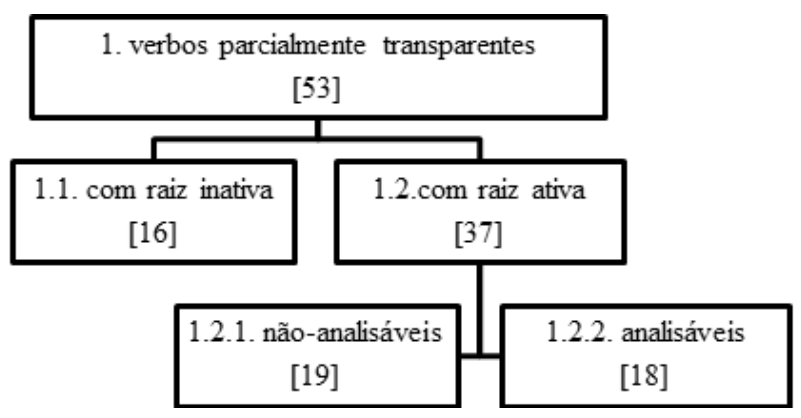


Antes de entrar propriamente nas subdivisões que propomos, é importante caracterizar o conjunto geral de verbos parcialmente transparentes. Para tal, é preciso retornar um pouco na história a fim de entender o papel dos prefixos nessas formações desde sua entrada na língua. O sistema preposicional latino (assim como parte dos advérbios) é um desenvolvimento do sistema de caso. Os casos genitivo, dativo e ablativo, atribuídos a DPs (Determiner Phrase / Sintagma Determinante) com função de objetos verbais, eram usualmente realizados como sufixos nominais (CARO; CUERVO, 1972, p. 239); entretanto, com o enfraquecimento das desinências de caso, o uso dos advérbios emergiu como uma forma de indicar mais precisamente as relações entre o verbo e seus objetos. Alguns desses advérbios tornaram-se especializados como preposições, mas muitos mantiveram seu estatuto adverbial (ALLEN; GREENOUGH, 1979). Em especial, de nosso interesse são as preposições/prefixos latinos ad-, ex- e in-, que eram particularmente usados com os casos acusativo e ablativo. Os verbos parcialmente transparentes eram, em geral, verbos latinos prefixados por tais preposições a fim de indicar relações espaciais, especialmente direção. No exemplo a seguir, a preposição $a d$, sem estatuto morfofonológico afixal, combina-se com diferentes verbos para estabelecer uma relação semântica e estrutural entre esses e o DP. 0 negrito em (5) indica a marca morfológica de caso no substantivo.
a. Veni ad urbem. (Vir à cidade)
b. Manere ad meridiem. (Esperar até meio-dia)
c. $A d$ focum sedere. (Sentar próximo ao fogo)

No caminho para as línguas românicas, na medida em que a marcação fonológica de caso foi desaparecendo, formas como as en (6), em que não há marca de caso nos substantivos, tornaram-se possíveis:
a. Veni ad Roma (Venho para Roma)
b. Veni ab Roma (Venho de Roma)
c. Veni ex Roma (Saí de Roma)

Como um desenvolvimento, preposições puderam se anexar aos verbos, como prefixos, por exemplo em (7), abaixo, em que há a combinação do prefixo ad-e do verbo venire, resultando no verbo prefixado advenire. 
advenio,-i,-tum,-ire i.q. accedo, ad aliquem locum venio, pervenio ${ }^{2}$

'aproximar-se, ir a algum local, chegar a'

Desse modo, muitos desses verbos entraram na língua portuguesa já como verbos compostos (no sentido de complexos). Tais formações são derivadas, mas nem sempre são totalmente transparentes na sincronia atual. Em muitos casos, esses verbos adquirem significados diversos do que se esperaria a partir de sua composição latina, como é o caso do verbo português advir. Comparem-se as acepções em (7) e (8):

(8) advir: port. vir depois, surgir como consequência de, provir, resultar, ocorrer, suceder, acontecer.

A questão relevante que se coloca, então, é se poderíamos pensar em uma nova raiz sincrônica para esses verbos em vez de analisá-los como formas complexas. A seguir, propomos que tais dados se subdividem em dois tipos: os que ainda podem permitir uma análise como formação composicional sincrônica e os que foram totalmente reanalisados como formações simples.

\subsection{VERBOS PARCIALMENTE TRANSPARENTES COM RAIZ INATIVA OU VERBOS SIMPLES}

Apesar de formalmente identificados como verbos latinos prefixados e de ser possível chegar à identificação de um prefixo em uma derivação etimológica, os verbos desse grupo são formações sincrônicas simples, em que o suposto prefixo é, atualmente, parte da raiz. A raiz, nesse caso etimológica, não se faz presente em nenhuma outra formação em que se mantenha um mesmo significado de um modo minimamente coerente. Em algum estágio da língua, que não temos por objetivo identificar, o prefixo incorporou-se à base e, no processo de aquisição, adquiriu-se uma nova raiz na Lista 1, o Inventário de raízes e núcleos funcionais da língua ${ }^{3}$. As ocorrências desse tipo são verbos como adquirir, esquecer e afetar. A totalidade dos dados encontra-se no Anexo I.

2 BLATT, R.; HEMMINGSEN, R. Vademecum in opus Saxonis et alia opera Danica compendium ex indice verborum: Medieval Latin dictionary. Silkeborg: Rostra, 1997.

3 Para exemplificação rápida sobre a arquitetura da gramática no modelo da MD, cf. Morfologia Distribuída. Disponível em: < http://gremd.fflch.usp.br/node/8> . Acesso em: 18 maio 2015. 
Tais casos encontram-se no extremo máximo da não-transparência ou opacidade, que podemos tratar como um continuum. São verbos cuja suposta raiz não tem distribuição coerente além de uma única ocorrência concomitantemente à ocorrência de afixos. Observemos alguns exemplos com a formação etimológica dos verbos afetar, adquirir e esquecer, simplificadamente descrita da seguinte forma, do latim à forma portuguesa (HOUAISS, 2007):

(9) ad + facěre $>$ adfacěre $>$ affectare $>$ affectar $>$ afetar

(10) $\mathrm{ad}+$ quaerěre $>$ adquaerěre $>$ adquirěre $>\ldots>$ adquirir

(11) ex + cadere $>$ excadere $>$ *excadescěre ${ }^{4}$

Nesses casos, em algum ponto, o prefixo incorporou-se à raiz gerando uma nova entrada na Lista 1 da língua. Abaixo, apresentamos um diagrama simplificado de como hipotetizamos que tenha ocorrido tal mudança.

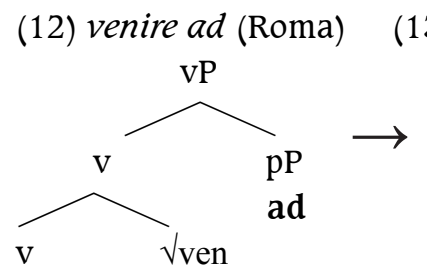

13) advenire'5

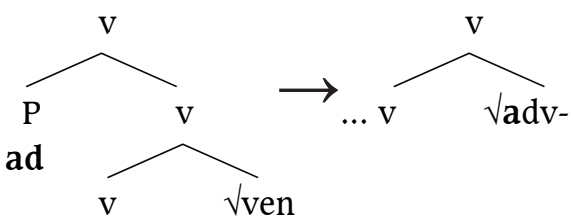

A estrutura em (12) representa um verbo simples em latim. Esse verbo é composto de uma raiz e um núcleo funcional verbalizador. o complexo em $\mathrm{v}$ toma um argumento interno do tipo preposicionado, como no exemplo em (5)a. acima.

Nesse exemplo, os núcleos v e p são morfofonologicamente independentes (ad-é uma preposição, e não um prefixo ). Já em (13), o estatuto do núcleo que realiza ad- muda de cíclico para não-cíclico, no próprio latim, nos termos de Embick (2010), se tornando um prefixo do núcleo v. Observamos, então, uma primeira modificação da estrutura ${ }^{6}$.

Nesse caso, vemos que o estatuto morfofonológico do elemento que era preposição se altera. Entretanto, é preciso investigar se há alguma

4 Verbo "frequentativo" de excadere ("cair para fora").

5 Segundo o dicionário Escolar Latino-Português, esse verbo é usado como intransitivo ou pode ter complementos indiretos. Nesse último uso, a preposição ad- pode ocorrer novamente em advenire ad Roma. Tal fato é evidência do desaparecimento funcional da camada que continha ad-, um tipo de redundância que é fruto da mudança.

6 Não discutiremos aqui questão da ordem superficial dos núcleos. Para tal discussão, cf. Bassani (2013, cap. 5). 
mudança na função estrutural desse elemento. Há duas hipóteses naturais: i. a sua capacidade de tomar um complemento e relacioná-lo ao verbo se perde, sendo necessária uma nova preposição que introduz o argumento interno: nesse caso, o verbo passa (ou continua a ser) um verbo transitivo indireto; ii. sua função relacionadora não se perde e há algum tipo de estrutura verbal complexa interna em que um elemento de natureza relacionadora toma um argumento interno. Há diversos casos em que prefixos e partículas, apesar de incorporados a uma estrutura morfofonológica verbal complexa, podem tomar argumentos internos como complementos. Exemplos clássicos desse tipo estrutural são as estruturas depreposicionais de Hale e Keyser (2002, p. 7). Bassani e Minussi (2015) também apresentam uma série de evidências empíricas que mostram que não são as raízes ou os verbalizadores os elementos responsáveis por introduzir o argumento interno na estrutura de verbos complexos. No caso acima, o verbo advenio é classificado como intransitivo pelas gramáticas latinas, podendo não tomar nenhum complemento ou tomar um complemento preposicionado (por ad ou in, por exemplo). Nos parece, então, que essa classificação indica que a mudança de estatuto morfofonológico é acompanhada de uma mudança de função, a descrita na hipótese ii.

Finalmente, em (14), já pensando na formação do português, o núcleo não-cíclico $P$ é completamente incorporado à raiz, já que não se pode mais utilizá-lo como elemento preposicional livre. Isso resulta em uma etapa de perda de estrutura, que já se poderia se configurar como uma opção quando da entrada desse verbo no português e que se especificou nessa língua. Uma consequência dessa mudança é o fato de que esse verbo é transitivo indireto, ou seja, a preposição de tem de introduzir o argumento interno (advir de). Outros exemplos em que se poderia testar a mesma hipótese de mudança são outros casos em que há uma aparente reduplicação da forma prefixal, tais como concordar com, destituir de, depor de, ascender a etc. ${ }^{7}$

Algumas observações se fazem necessárias com relação à nossa teoria de um desaparecimento funcional do prefixo, que passa a se integrar à raiz, apesar de sua fonologia continuar aparente. Nossa proposta é, obviamente, em termos mais gerais, um tipo de proposta de lexicalização. Tal processo permite a criação de uma nova raiz no repertório da língua por meio de simplificação estrutural (ROBERTS; ROUSSOU, 2003). Para além do processo normal de aquisição, outras formas de adquirir novas raízes no repositório vocabular ocorrem com a criação de neologismos e empréstimos.

7 Um dos pareceristas anônimos aponta questões relevantes acerca da mudança de preposição para prefixo, mas que fogem ao objetivo principal deste trabalho, bem como esbarram em suas limitações de espaço. Essas questões concernem, sobretudo, à investigação da motivação para tal mudança e por que se dá a escolha pela forma prefixal em vez de sufixal ou infixal. Essas questões permanecem para investigação futura. 
Segundo Roberts e Roussou (2003), o processo de gramaticalização também deve ser entendido como um processo de simplificação estrutural de estruturas sintáticas subjacentes, e é exatamente o que propomos especificamente para esse caso de lexicalização ${ }^{8}$. Um nível de projeção cujo núcleo era provavelmente o prefixo deixa de existir e passa a fazer parte da raiz, resultando, então, em uma nova raiz. Por isso, a raiz diacrônica não está mais disponível para a formação de palavras, mas a raiz reanalisada está, como se nota pela possível formação de palavras derivadas a partir dessas raízes (afetação, adquirente, esquecimento, advindo etc.). Por conta disso, os falantes têm enorme dificuldade, ou nenhuma possibilidade, em muitos casos, de reconhecimento do suposto prefixo.

Seguindo os pressupostos da MD, os núcleos funcionais são conjuntos de traços gramaticais, morfossintáticos e morfossemânticos. Os núcleos preposicionais são, em um dos usos de sua origem histórica, portadores de informações direcionais/locativas. Quando há um processo de lexicalização desse tipo de núcleo, ou seu conteúdo de traços pode ser completamente obliterado na raiz reanalisada, restando somente a fonologia do item, ou tais traços podem ainda ser totalmente ou parcialmente preservados. Um exemplo em que se preserva alguma denotação do prefixo é o do verbo engolir. Observemos a sugestão de etimologia segundo o dicionário Houaiss:

Engolir: prov. lat.vulg. *ingullare (it. ingollare, fr. engouler, provç. engolar, esp. engullir); ver gul-. antepositivo, do lat. gula,ae 'parte da boca pela qual se engole, goela, garganta, pescoço; boca (linguagem popular).

Engolir se origina de um verbo complexo de tipo de mudança de lugar (location), em que a raiz denotava o lugar. Posteriormente, a raiz diacrônica não se atualizou como forma sincrônica e esse verbo não pôde ser decomposto. Tal fato se comprova pela possibilidade de termos algo como "engolir pela boca", em que se especifica o local que outrora fora denotado de modo transparente pela raiz. No entanto, é possível apreender a noção de movimento para dentro lexicalizada agora na raiz, como fruto de um resquício histórico.

Diferentemente, em alguns casos, são os traços do prefixo que deixam de figurar na raiz reanalisada. Exemplos com o núcleo preposicional a- são numerosos, pois seus traços já possuem um significado muito leve mesmo quando ativos. Na incorporação, é difícil encontrar a sua contribuição. São alguns exemplos verbos como acessar, afastar, afetar.

8 Agradecemos a Marcus Vinicius Lunguinho por nos apresentar a proposta de Roberts e Roussou (2003) e atentar para a possível relação entre nossa proposta e as ideias ali introduzidas. 
Outro fato interessante diz respeito à morfologia: em alguns casos, o afixo que passa a ser incorporado pode manter a sua forma diacrônica, como ocorre nos exemplos com ad- e in-. Noutros casos, a raiz também pode apresentar-se em uma forma arcaica, diferente da raiz reanalisada. Tais formas arcaicas não estão disponíveis para a formação de neologismos no sistema sincrônico do português. Um exemplo interessante é o dos verbos afetar e infectar. Apesar de, em ambos os casos, a derivação etimológica consistir na prefixação de uma mesma raiz verbal, originaram-se duas raízes diferentes ( INFECT- e $\sqrt{\text { AFET- }}$ ).

Para finalizar, e como embasamento adicional para a nossa análise do que chamamos de verbos prefixados que foram reanalisados como verbos simples, apresentaremos de forma breve uma discussão sobre como se dá o "desaparecimento" de prevérbios em formações complexas nas diversas línguas do mundo. A passagem de um prevérbio a parte integrante da raiz do verbo é um processo comum e largamente documentado. Acreditamos que os casos de que tratamos imediatamente acima são também um tipo de manifestação desse processo.

O termo prevérbio foi cunhado pelos descritivistas do Indo-Europeu para designar morfemas que se posicionavam frente ao verbo e formavam com ele uma unidade de sentido. A partir de então, o termo foi usado para descrever muitos morfemas de diversas línguas que se comportavam como parte integrante da noção verbal. O prevérbio pode se manifestar de duas maneiras: como palavra livre ou como morfema preso. No primeiro caso, ele pode inclusive ser separado do verbo por outros elementos; temos, nesse tipo, a formação de um predicado complexo (15). No segundo caso, dá-se a formação de um verbo complexo propriamente dito, em que verbo e prevérbio nunca se dissociam (16) (BOOIJ; KEMENADE, 2003).

(15) Predicado complexo = \#Prevérbio (\#) (...) (\#) Verbo\#

(16) Verbo complexo = \#Prevérbio-Verbo\#

O termo prevérbio pretende se especializar nos tipos de prefixos verbais de natureza derivacional que, grosso modo, são morfemas que contribuem com alguma semântica adicional à formação final. $O$ termo prefixo (verbal) é mais geral, pois abrange também morfemas flexionais que se realizam à frente do verbo em muitas línguas. No Georgiano, por exemplo, a ordem dos elementos internos à forma verbal é a apontada abaixo, em que prevérbios e prefixos (em geral elementos flexionais) co-ocorrem (AMIRIDZE, 2004): 
(17) Prevérbio-prefixo.de.concordância-vogal.pré.radical-Raiz -Sufixo tempo

da-v-e-c-i

PV-S1.SG-PRV-fall-AOR ${ }^{9}$

I fell down. ${ }^{10}$

'Eu caí.'

Assim, há de se apreender que nem todo prefixo verbal é um prevérbio. No entanto, muitos autores ainda utilizam a terminologia prefixo verbal para tratar de morfemas que se comportam como prevérbios (como é o caso de Svenonius (2004), por exemplo), em especial nas línguas que não possuem morfologia flexional realizada como prefixo.

Com relação ao que se investigou sobre o desenvolvimento dos prevérbios ao longo da história de cada língua, constatou-se que, em muitas delas, essas partículas foram formas independentes em um estágio anterior. Nessas línguas, em geral, os prevérbios podem se comportar como prevérbios de fato ou como preposições. Hipotetiza-se que ambas as formas tenham origem adverbial. Os diversos estágios de desenvolvimento dessas partículas resultam na variedade de formas de realização entre as diversas línguas. Algumas delas ainda apresentam prevérbios como fortes elementos preposicionais, em outras há prevérbios que ora se posicionam junto ao verbo, ora estão separados por determinadas construções sintáticas e outras vezes, ainda, são prefixos indissociáveis; finalmente, há outras que apresentam todas essas formas ao mesmo tempo.

Segundo Booij e Kemenade (2003, p. 3), em algumas línguas os prevérbios mantêm intactos por um longo tempo seu caráter de forma independente, enquanto outras apresentam um clássico processo no seguinte sentido:

(18) prevérbio independente $>$ membro à esquerda de um composto verbal $>$ prefixo $>$ desaparecimento

Segundo Vincent ${ }^{11}$, (1999, p. 1118), apud Booij e Kemenade (2003), tal processo é facilmente identificável na história dos prevérbios do latim. $O$ autor mostra que, em estágios iniciais dessa língua, os prevérbios tinham caráter de forma livre, como se observa em (19) a partir de trechos da obra do gramático Festus a respeito da linguagem dos oradores antigos.

$9 \quad \mathrm{PV}=$ prevérbio

10 Optamos por apresentar nos exemplos as traduções originais dos autores e, em seguida, a tradução para o português.

11 VINCENT, N. The evolution of c-structure: prepositions and PPs from Indo-european to Romance. Linguistics, v. 37, n. 6, p. 1111-1154, 1999. 
Em estágios posteriores, eles tornaram-se membros de radicais verbais compostos e, finalmente, adquiriram caráter prefixal:

(19) Prevérbios latinos livres

a. Sub vos placo, in precibus fere cum dicitur, significat id, quod supplico

'when people say, mostly in prayers, sub vos placo, it means the same as supplico' ('quando as pessoas dizem, na maior parte em orações, sub vos placo, isso significa o mesmo que supplico')

b. $O b$ vos sacro, in quibusdam precationibus est, pro vos obsecro, ut sub vos placo, pro supplico.

'ob vos sacro in certain prayers stands for vos obsecro, just as sub vos placo satnds for supplico' ('ob vos sacro em algumas orações corresponde a vos obsecro, assim como sub vos placo corresponde a supplico')

(20) Prevérbios latinos como parte de um radical verbal composto passando a prefixos:

Submittere; permittere; transmittere; transferre; perferre; obligare Submeter; permitir; transmitir; transferir; realizar; vincular

Nossa contribuição é mostrar que, para a progressão em (18), existem duas alternativas: a do desaparecimento formal e funcional total, como ali previsto, e a da incorporação, que pode levar ao apagamento (com ou sem preservação parcial) dos traços gramaticais e semânticos do prefixo (e da raiz), fazendo com que a formação, antes composta, deixe de assim o ser na sincronia. Esse segundo caso é o que melhor descreve a mudança sofrida por nossos dados. Tentamos mostrar, a título de comparação, que podemos aplicar, com alguns ajustes, a progressão em (18) aos dados tratados. Retomando o exemplo com advenire, nos moldes de (18), e adaptando o fato de que o prevérbio se inicia como uma forma independente posposta, temos o seguinte percurso.

(21) Forma independente (venire ad) > membro à esquerda de um composto verbal (advenire) > prefixo (advernire) $>$ desaparecimento funcional (advenire $a d)$ 
Tais formas já entram no sistema do português como formas simples, apesar de serem linguisticamente analisáveis. Novamente, uma evidência para isso é o fato de que o complemento do verbo advir deve ser introduzido por uma preposição nessa língua: advém de.

Em resumo, tratamos nesta subseção de verbos diacronicamente complexos e sincronicamente simples formados por perda (parcial/total) dos traços semânticos dos afixos e raízes e da geração de um significado reanalisado com possibilidade de manutenção de partes dos significados prévios.

\subsection{Verbos Parcialmente transparentes com raiz ativa: Verbos ANALISÁvEIS E Verbos NÃo-ANALISÁveIS}

Nesta seção, fazemos uma proposta de divisão entre verbos com raiz ativa analisáveis e verbos com raiz ativa não analisáveis. As raízes presentes no segundo tipo são sincronicamente isoláveis e, por isso, tais formas podem ser de algum modo ainda complexas. O critério para considerar tais raízes ativas se baseia em dois fatores dependentes: a) a possibilidade de comutação, que mostra que estão ativas, e b) a manutenção de um significado compartilhado na comutação. Apenas em um subgrupo de 17 verbos os critérios (a) e (b) se aplicam sem problemas. Em um outro subgrupo, não se identifica facilmente a composicionalidade, apesar de ser fato que a raiz se encontra em outras formações da língua. Vamos a alguns exemplos mais concretos.

\subsubsection{Verbos analisáveis COM A) POSSIBILIDAde DE COMUtAÇÃo E B) SIGNIFICADO COMPARTILHADO DA RAIZ}

Quando uma mesma raiz está presente em mais de uma formação parcialmente transparente e, ao compararmos essas palavras, mantém-se a mesma contribuição semântica para a formação final, podemos falar de uma forma parcialmente transparente analisável. Um exemplo claro é o dos verbos formados pela raiz $\sqrt{T R A}-$. Apesar de ser fato que os verbos que contêm essa raiz não foram compostos nativamente em português, pode-se lançar a hipótese de que eles ainda são analisáveis por alguns falantes. Observemos os dados em (22):

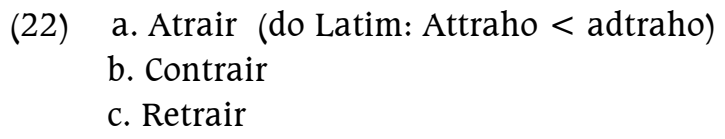




\section{d. Abstrair \\ e. Extrair}

Nas formações acima, um significado abstrato pode ser atribuído a $\sqrt{T R A}$; no entanto, esse significado é um tanto maleável no sentido de que se atualiza completamente com o significado atribuído pelos prefixos. Este é outro ponto importante: ao contrário das formações com raiz inativa abordadas na subseção anterior, nesses dados podemos perceber mais claramente a contribuição dos prefixos. Desse modo, as formações de (22), em tese, podem ser decompostas, mas não se pode esperar um significado completamente determinado delas, pois a raiz e, por vezes, os afixos contribuem com noções um tanto abstratas. Tal fato se dá porque quando as formas são completamente transparentes, podemos isolar a raiz em paráfrases (avermelhar $=$ tornar vermelho, empilhar = fazer pilha de), o que não se pode fazer com relação aos que incluem a raiz $\sqrt{T R A}$, por exemplo.

Se assumirmos que a competência do falante decorre da organização da gramática como sugerida pela MD, assumir que cada um dos dados em (22) apresenta uma raiz reanalisada como entradas distintas na Lista 1 a partir da mesma raiz diacrônica $\sqrt{\text { tra- }}$ ( $\sqrt{\text { ATRA-, }}$ CONTRA-, $\sqrt{ }$ RETRA-,

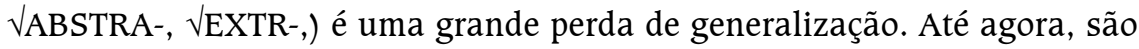
dois os motivos para assumir a ideia de que tais verbos são ainda composicionais: a possibilidade de comutação e, a partir disso, a manutenção de uma semântica minimamente compartilhada pelas raízes e pelos afixos. Uma terceira evidência de que temos a realização de uma mesma raiz está no fato de que, em todas as formações, mantêm-se a escolha da mesma vogal temática verbal, de terceira conjugação: a reanálise total da raiz poderia ter levado a uma reanálise morfológica. Sabe-se que a definição da vogal temática verbal é idiossincrática e é responsabilidade da raiz (a não ser que sufixos verbais se apresentem (BASSANI, 2013)). Assim, a reanálise da raiz poderia levar a uma mudança na escolha da vogal temática para a primeira classe, default, o que não ocorre. Essa possibilidade, somada às duas evidências anteriores, nos leva a assumir tal posição, apesar de sabermos que se trata de uma possibilidade e, por isso, não é uma evidência cabal.

Assim, levantamos a hipótese de que dados como os formados pela raiz $\sqrt{T R A}$ - são composicionais e possuem uma estrutura mais complexa do que a dos dados em 2.1. Em continuidade, não podemos prosseguir sem dizer que esses são os dados exemplares, os dados de comportamento ideal. Por outro lado, algumas raízes parecem ocupar uma posição intermediária entre os completamente reanalisados e os completamente analisáveis. Consideremos o exemplo de raízes que não têm uma ampla capacidade de distribuição,

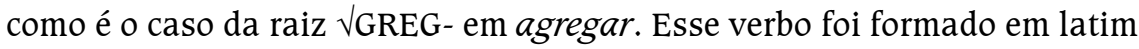


como em (23), e tem uma distribuição restrita em formas atuais como as de (24), em que $\sqrt{G R E G-~ e ́ ~ u m ~ e l e m e n t o ~ p r i m i t i v a m e n t e ~ r e l a c i o n a d o ~ a ̀ ~ i d e i a ~ d e ~}$ reunir, especialmente gado, "rebanho" (VIARO 2004, p. 22).

(23) adgregare > aggregare > agregar

Vademecum: aggregare $=$ coniungere (terras suo regno) Gertz M I,66,13
a. segregar
b. congregar

Apesar de ter uma distribuição mais restrita, é possível que os dados em (24) sejam ainda formas composicionais. Todas as formações classificadas como verbos com raiz ativa têm em sua forma diacrônica a raiz de um verbo latino. Por isso, em sua gênese, tratava-se de verbos prefixados e não de verbos parassintéticos propriamente. Veja a lista abaixo com alguns dos dados (a totalidade está disponível no Anexo I):

(25) Verbos possivelmente analisáveis:

$\begin{array}{lll}\text { 1. } & \text { agregar (vs. segregar, congregar) } & \text { VT -a- } \\ \text { 2. } & \text { atrair (vs. extrair, contrair...) } & \text { VT -i- } \\ \text { 3. } & \text { evadir (vs. invadir) } & \text { VT -i- } \\ \text { 4. } & \text { exalar (vs. inalar) } & \text { VT -a- } \\ \text { 5. } & \text { excluir (vs. incluir) } & \text { VT -i- } \\ \text { 6. } & \text { expirar (vs. inspirar) } & \text { VT -a- } \\ \text { 7. } & \text { extrair (vs. atrair, retrair...) } & \text { VT -i- } \\ \text { 8. } & \text { ingressar (vs. regressar) } & \text { VT -a- }\end{array}$

Uma possível contra-argumentação para essa análise seria o fato de que essas raízes nunca ocorrem na língua como palavras independentes, e recorrer a elas seria utilizar um tipo de recurso histórico em uma análise que se pretende sincrônica. Entretanto, assumimos que essas raízes podem ser parte do repertório de raízes do $\mathrm{PB}$, mas nunca ocorrem isoladamente porque não estão listadas como entradas válidas independentes na Enciclopédia. Raízes como essas só podem ser interpretadas quando no contexto de outros elementos. Tomamos esse argumento de análises como a de Borer (2009) para os compostos sintéticos do tipo truck-driver do inglês: a autora assume um constituinte sem categoria, truck-drive, que é categorizado como um conjunto. Esse elemento não pode ser interpretado isoladamente porque não está listado independentemente, sem um contexto de inserção, na Enciclopédia. Nesse sentido, esse seria um composto formado a partir de raízes. Os casos de redundância, exemplificados abaixo, de (26) a (31), que ocorrem em variedades do português, parecem ser um contraexemplo 
para a assunção de que tais formas são composicionais. A possibilidade de redundância da informação direcional nos parece uma evidência de um processo de mudança, e por isso falamos anteriormente em um continuum: a classificação sugerida aqui é uma abstração analítica. Nos parece óbvio que os verbos podem passar de formas analisáveis a formas simples, pois estão sujeitos ao processo de perda de estrutura. Em outras palavras, é muito plausível que, para o repertório de raízes de alguns falantes, esses dados não sejam mais composicionais de fato. A mudança, nesse caso, indica que a direcionalidade que era antes codificada na raiz passa a ser codificada fora do verbo.
(26) Extrair $\mathrm{p}(\mathrm{a}) \mathrm{ra}$ fora
(27) Inserir $\mathrm{p}(\mathrm{a}) \mathrm{ra}$ dentro
(28) Atrair $\mathrm{p}(\mathrm{a})$ ra perto
(29) Expelir $\mathrm{p}(\mathrm{a}) \mathrm{ra}$ fora
(30) Subir p(a)ra cima
(31) Descer $p(a)$ ra baixo

\subsubsection{Verbos COM A) POSSIBILIDAdE DE COMUTAÇÃo MAS SEM B) SIGNIFICADO COMPARTILHADO DA RAIZ: NÃO ANALISÁVEIS}

Outros dados com raiz ativa não apresentam uma possível semântica composicional, como ocorre com os dados em (25), apesar de sua raiz estar presente em outras formações do português, parecendo ocupar um limbo entre uma forma analisável e uma forma que foi reanalisada. Um bom exemplo é o do verbo agredir, cuja raiz ainda figura em regredir e progredir. Em regredir e progredir, há um par do tipo analisável em que se nota uma oposição dada pelos prefixos e um significado eventivo compartilhado e coerente proveniente da raiz. Entretanto, tal contraste não se dá na sincronia com o verbo agredir, que significa algo como um "ataque verbal ou físico". Certamente, o prefixo a- tem participação diacrônica na presença de um argumento para o qual a ação é direcionada, mas tal assunção não se aplica hoje com facilidade. Para esse caso, nos pareceria mais plausível sugerir uma reanálise do tipo proposto em 2.1. e a aquisição de uma raiz $\sqrt{\text { AGRE(D). Contudo, sugerimos }}$ que a raiz sincrônica para regredir e progredir seja $\sqrt{G R E(D), ~ u m a ~ r a i z ~ q u e ~}$ só pode se atualizar no contexto de outros elementos (propriedade listada na enciclopédia) e não mais a raiz originária $\sqrt{g r a d}$.

Possivelmente, tais dados ocupam uma etapa atual rumo à reanálise e, por isso, é tão difícil classificá-los de forma estanque como formas reanalisadas ou analisáveis. Hipotetizaremos que tais dados ou caminham 
para a classificação como formas reanalisadas em uma sincronia futura próxima ou já são reanalisados. No diagrama retomado acima, buscamos representar tal relação pela flecha que os liga aos verbos simples reanalisados. Desse modo, tendemos a superclassificar os dois tipos como formas simples. Pertencem a esse subgrupo verbos como administrar, aferir, agredir, atender (a totalidade dos dados está no Anexo I).

Com isso, concluímos nossas reflexões acerca de como procede a mudança de formas complexas para formas não complexas envolvendo prefixos.

Em suma, identificamos 2 subtipos mais gerais de verbos parcialmente transparentes no que se refere ao comportamento frente à transparência morfológica e à composicionalidade semântica:

\begin{tabular}{|cccc|}
\hline Transparente & Composicional & Classificação & Exemplos \\
\hline & & Simples por deri- & afetar, esquecer, \\
& & vação histórica & inundar \\
- & + & Complexos Anali- & atrair, incluir, \\
& & sáveis & exibir
\end{tabular}

Apesar de não ser nosso foco neste momento, atentamos para o fato de que o mesmo processo de lexicalização em termos de perda de estrutura ocorre com sufixos. Esse é o caso do verbo esquecer na sincronia, por exemplo, no qual o sufixo -ec- não tem funcionalidade. Em suma, os fatores que levam à reanálise são o apagamento de traços semânticos do afixo ou da raiz que, por sua vez, leva à incorporação ou fusão do que eram dois elementos estruturais (um núcleo prefixal e uma raiz) em uma única raiz reanalisada. Tal operação resulta em perda/simplificação de estrutura, entendida por Roberts e Roussou (2003) como a fonte do processo de gramaticalização e que pode ser estendida ao tipo de processo de lexicalização de que tratamos. No produto resultante desse processo, podemos recuperar traços semânticos do núcleo funcional relacional/prefixal (engolir), ou pode haver uma completa ressignificação (afetar).

\section{CONSIDERAÇõES FINAIS}

Acquaviva e Panagiotidis (2012) argumentam que nenhum significado ou conteúdo semântico pode ser atribuído às raízes fora de uma estrutura gramatical, em oposição às assunções padrões em MD, que defendem que raízes são dotadas de significado. Utilizam-se de exemplos muito 
similares aos que abordamos: são morfemas presos do italiano e do inglês (cran-morphs na terminologia descritiva de Aronoff (1976)). Assumem que elementos do inglês, como-ceive, -mit ou-verse em conceive, receive, admit, permit, converse e perverse, e do italiano, como mett- em dimettere, smettere, scomettere, são exemplos da maleabilidade semântica das raízes. Ainda, ao apresentarem um longo paradigma do grego" ${ }^{12}$, assumem que "roots are not meaning signs" ("as raízes não são signos dotados de significado"):

"Despite the illusory affinities suggested by the Latinate English glosses (G. Longobardi, p.c.), the class of concepts words derived from esth- is broad enough to render impossible the task to associate the root itself with any kind of cognitively coherent concept, no matter how underspecified or vague, and even to the exclusion of 'beautician'” (p. 6). ${ }^{13}$

Concordamos com a ideia de maleabilidade, mas acreditamos que a assunção dos autores de que as raízes não têm significado é demasiadamente radical e simplista. Em nossa abordagem, tentamos mostrar que o caminho para que uma raiz se torne um elemento obliterado de significado se dá em estágios. Em alguns casos, uma reanálise completa se aplica; mas assumir que todas as raízes são completamente vazias, mesmo que formem um paradigma semântico vagamente relacionado, porém amplo, como é o caso dos dados apresentados, nos parece, como diz o ditado, "jogar o bebê fora com a água da banheira”, e perder a chance de generalizar um importante processo de mudança pelo qual as raízes e os elementos funcionais passam. Por isso, discordamos de Acquaviva e Panagiotidis (2012).

12 Paradigma envolvendo o elemento grego esth-:

a) esth-an-o-me 'feel' (sentir);

b) esth-is-I 'sense' (sentido);

c) sin-esth-is-i 'realisation', 'awareness' (realização, consciência);

d) 'esth-i-ma 'feeling', 'love affair', 'boyfriend / girlfriend' (sentimento, caso amoroso, namorado/a);

e) sin-esth-i-ma 'emotion' (emoção);

f) esth-is-iaz-mos 'sensuality' (sensualidade);

g) esth-an-tik-os 'sensitive, emotional' (sensível, emocional);

h) esth-it-os 'perceptible', 'tangible' (perceptível, tangível);

i) an-esth-it-os 'unconscious', 'insensitive' (inconsciente, insensível);

j) esth-it-ir-ios 'sensory' (sensorial);

k) esth-it-ik-os 'esthetic', 'beautician' (estético, esteticista).

13 "Apesar das afinidades ilusórias sugeridas pelas glosas inglesas de origem latina (G. Longobardi c.p.), a classe de palavras conceituais derivadas de esth-é suficientemente ampla para tornar impossível a tarefa de associar a raiz por si só a qualquer tipo de conceito cognitivamente coerente, não importa quão subespecificado ou vago, mesmo com a exclusão de 'beautician'."(Tradução nossa). 
No que se refere à transparência, dois fenômenos formais parecem corroborar nossa proposta de divisão: a distribuição dos alomorfes arcaicos e das vogais temáticas de terceira conjugação. Os alomorfes ad- e in- e a forma arcaica grafada $e x$ - aparecem majoritariamente nas formas parcialmente transparentes. Dos 53 verbos parcialmente transparentes, 27 ocorrem com tais formas, totalizando aproximadamente $51 \%$ dos dados, ao passo que, nos verbos transparentes, apenas 14 verbos ocorrem com tais formas em um total de 328 verbos, totalizando aproximadamente 4\% (Para os verbos transparentes e composicionais, cf. Bassani (2013)).

Tabela 2 - Formas prefixais vs. transparência

\begin{tabular}{ccc}
\hline Forma prefixal & Parc-transparente & Transparente \\
\hline ad & 2 & 0 \\
$e x$ & 9 & 4 \\
in & 16 & 10 \\
Outros $(a-, e n-, e s-)$ & 26 & 313 \\
\hline & 27 de 53 & 14 de 327 \\
Total & $51 \%$ & $4 \%$ \\
\hline
\end{tabular}

Com relação às vogais temáticas, sabemos que as vogais de segunda e terceira conjugações não são mais formas produtivas na sincronia do português, estando restritas a um conjunto menor de verbos. A vogal temática de primeira conjugação, por outro lado, é ativa e capaz de formar neologismos. A escolha da vogal temática de segunda conjugação -e-é potencializada pela presença do sufixo -ec-, presente sobretudo em verbos de mudança de estado e, por isso, sua alta representatividade nos verbos transparentes. No entanto, o fato mais interessante é a alta representatividade da vogal temática de terceira conjugação nas formas parcialmente transparentes. Em contraste, nos verbos transparentes há uma alta incidência da vogal temática de primeira conjugação: 286 ocorrências de 311, um total de aproximadamente $91 \%$. Assim, existe uma forte correlação entre maior transparência e primeira conjugação e menor transparência e terceira conjugação.

Tabela 3 - Vogais temáticas vs. transparência e composicionalidade

\begin{tabular}{cccc}
\hline Vogal Temática & Parc. transparentes & Transparentes & Total \\
\hline I - a & 25 & 285 & 310 \\
II - e & 5 & 42 & 47 \\
\hline Total & 53 & 327 & 380 \\
\hline
\end{tabular}




\begin{tabular}{cccc}
\hline Vogal Temática & Parc. transparentes & Transparentes & Total \\
\hline III $-\mathrm{i}$ & 23 & 0 & 23 \\
\hline Total & 53 & 327 & 380 \\
\hline
\end{tabular}

Tanto as formas arcaicas dos alomorfes prefixais como a vogal temática de terceira conjugação são tidas como peças não produtivas na sincronia da língua. Apesar disso, encontramos um subgrupo dos verbos parcialmente transparentes, o dos verbos analisáveis, que aparentemente se comporta como os verbos composicionais no que se refere à contribuição dos afixos.

\section{REFERÊNCIAS}

ACQUAVIVA, P.; PANAGIOTIDIS, P. Lexical decomposition meets conceptual atomism. Lingue e Linguaggio, XI, n. 2 , p.165-180, 2012.

ALLEN, J.H.; GREENOUGH, J.B. Allen and Greenough's New Latin grammar for schools and colleges, founded on comparative grammar. New Rochelle, New York: Caratzas Brothers, 1979.

AMIRIDZE, N. Verb forms inside verb forms. The case of the modern spoken georgian pro-verbs. In: INTERNATIONAL MORPHOLOGY MEETING, 11., 2004.

ARAD, M. Locality Constraints on the Interpretation of Roots: the Case of Hebrew Denominal Verbs. Natural Language and Linguistics Theory, v. 21, p. 737-778, 2003.

BASSANI, I.S.; MINUSSI, R.D. Contra a seleção de argumentos pelas raízes: nominalizações e verbos complexos. ReVEL, v. 13, n. 24, p. 139-173, 2015.

BASSANI, I.S. Uma abordagem localista para morfologia e estrutura argumental dos verbos complexos (parassintéticos) do português brasileiro. Tese (Doutorado em Letras) - Faculdade de Filosofia, Letras e Ciências Humanas, Universidade de São Paulo, São Paulo, 2013.

BOOIJ, G.; KEMENADE, A. V. Preverbs: an introduction. In: BOOIJ, G.; MARLE, J. Yearbook of Morphology. Dordrecht: Foris, 2003. p. 1-11.

BORER, H. Root Bound. CASTL University of Tromso, 2009. [handout].

CARO, M. A.; CUERVO, R. J. Gramatica de la Lengua Latina. Para el uso dos que hablam castellano. Bogota: Instituto Caro y Cuervo, 1972.

EMBICK, D. Localism versus Globalism in Morphology and Phonology. Cambridge: MIT Press, 2010.

HALE, K; KEYSER, J. Prolegomenon to a Theory of Argument Structure. Cambridge: MIT Press, 2002.

HALLE, M.; MARANTZ, A. Distributed Morphology and the pieces of inflection. In: HALE, K.; KEYSER, J. The View from Building 20. Cambrigde: MIT Press, 1993. p. 111-176.

HOUAISS, A.; VILLAR, M.S. Dicionário Houaiss da Língua Portuguesa. Rio de Janeiro: Objetiva, 2007. [CD-ROM]. 
MARANTZ, A. Phases and words. NYU, 2007. [manuscrito].

ROBERTS, I.; ROUSSOU, A. Syntactic Change: A Minimalist Approach to Grammaticalization. Cambridge: Cambridge University Press, 2003.

SVENONIUS, P. Slavic Prefixes inside and outside VP. Nordlyd, v 32, n.2, p. 205-253, 2004.

VIARO, M. E. Por trás das palavras: manual de etimologia do português. São Paulo: Globo, 2004.

\section{ANEXO I}

1.Verbos parcialmente transparentes

1.1. Verbos parcialmente transparentes com raiz inativa $=$ Simples por derivação histórica
1. inclinar
7. embaçar
13. esmiuçar
2. infectar
8. adquirir
14. acessar
3. inflamar
9. afetar
15. engolir
4. inundar
10. assentir
16. envergar
5. arredar
11. assistir
6. esquecer
12. esbarrar

\subsection{Verbos parcialmente transparentes com Raiz ativa}

1.2.1. Parcialmente transparente com raiz ativa, mas não analisável

Verbo seguido de outra ocorrência da mesma raiz sem formação de par mínimo com significado coerente $=$ nova raiz.
1. enunciar, anunciar
2. instaurar, restaurar
3. investir, revestir
4. apreender, 5. empreender
6. aprender, desprender
7. atender, entender
8. apagar, pagar
9. induzir, reduzir
10. administrar, ministrar
11. aplicar, 12. explicar
13. influir, afluir
14. inferir, 15. aferir
16. instruir, construir
17. assumir, consumir
18. agredir, regredir
19. encarregar, descarregar

(raiz latina nunci-)

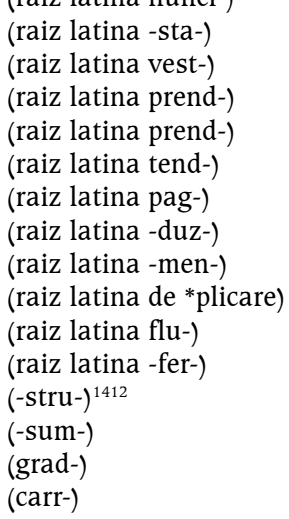

14 Construir e destruir podem ser considerados como pertencentes a um par mínimo e, nesse caso, estariam no tipo posivelmente analisáveis. 


\subsubsection{Parcialmente transparente com raiz ativa e possivelmente analisável}

$\begin{array}{lll}\text { 1. } & \text { agregar } & \text { (vs. segregar, congregar) } \\ 2 . & \text { atrair } & \text { (vs. extrair, contrair...) } \\ 3 . & \text { atribuir } & \text { (vs. retribuir, contribuir) } \\ 4 . & \text { evadir } & \text { (vs. invadir) } \\ 5 . & \text { exalar } & \text { (vs. inalar) } \\ 6 . & \text { excluir } & \text { (vs. incluir) } \\ 7 . & \text { exibir } & \text { (vs. inibir) } \\ 8 . & \text { expelir } & \text { (vs. repelir) } \\ 9 . & \text { expirar } & \text { (vs. inspirar) } \\ 10 . & \text { explodir } & \text { (vs. implodir) } \\ 11 . & \text { extrair } & \text { (vs. atrair, retrair) } \\ 12 . & \text { inalar } & \text { (vs. exalar) } \\ 13 . & \text { incluir } & \text { (vs. excluir) } \\ 14 . & \text { ingressar } & \text { (vs. regressar) } \\ 15 . & \text { inibir } & \text { (vs. exibir) } \\ 16 . & \text { inspirar } & \text { (vs. expirar) } \\ 17 . & \text { expulsar } & \text { (vs. impulsar/impulso) } \\ 18 . & \text { insistir } & \text { (vs. desistir) }\end{array}$

Submetido em: 12/02/2015

Aceito em: 22/02/2015 